\title{
On the Origin of Recent Intra-plate Volcanism in
}

\author{
Australia
}

\section{SUPPLEMENTARY MATERIAL}

\section{METHODS}

\section{TELESEISMIC TOMOGRAPHY}

The teleseismic tomography method assumes that relative arrival time residuals between simultaneously recording stations can be attributed to lateral variations in velocity in the upper mantle beneath the seismic array (Rawlinson et al., 2010). In this study, seismic structure is described by a crustal layer overlying a mantle half-space, with a seismic discontinuity (the Moho) separating the two media. P-wave velocity in both the crust and mantle is described by cubic B-spline functions tied to a 3-D regular grid of nodes; interface depth is defined in the same way, although a 2-D grid of nodes is needed to describe the discontinuity surface. The forward problem of arrival time residual prediction is solved using a grid-based eikonal scheme known as the Fast Marching Method (FMM) which is computationally efficient and robust (Rawlinson and Sambridge, $2004 b$,a). The inverse step is solved using a subspace scheme (Kennett et al., 1988) which is applied iteratively together with FMM to address the non-linearity of the problem (Rawlinson and Urvoy, 2006). In this case, only mantle P-wave velocity is inverted for, with both Moho geometry and crustal velocities held fixed. The maximum depth of good resolution is largely a function of array aperture; the larger the aperture, the greater the depth at which crossing path coverage occurs (see Rawlinson and Kennett, 2008, for more details). In this case, good resolution can be expected to a depth of approximately $300 \mathrm{~km}$, with features below a depth of about $350 \mathrm{~km}$ becoming poorly constrained.

\section{CRUSTAL STRUCTURE}

One of the drawbacks of teleseismic tomography is that the upper limit of depth resolution is approximately equal to the station spacing (Rawlinson and Sambridge, 2003). For the WOMBAT array (see Figure DR1), this is approximately $50 \mathrm{~km}$, which means that the crust is not well constrained, yet is likely to contain significant lateral variations in wavespeed that contribute to the measured arrival time residual. To account for this contribution, the AuSREM crustal and Moho models (Kennett and Salmon, 2012) are incorporated into the initial model used in the inversion. The AuSREM crustal and Moho models use a variety of sources, including ambient noise tomography, receiver functions, active source coincident reflection and wide-angle tomography, to constrain P- wave, S-wave and density variations in the crust. The grid spacing of the velocity field is $0.5^{\circ}$ in latitude and longitude and $5 \mathrm{~km}$ in depth. The Moho structure has 
identical horizontal resolution.

\section{MANTLE VELOCITIES}

Due to the use of relative arrival time residuals, teleseismic tomography is only capable of constraining relative variations in wavespeed (Rawlinson and Sambridge, 2003). When multiple datasets from a transportable array are used, only variations in velocity within a region approximately equal to or less than the aperture of the individual array will be recovered, and longer wavelength information will be lost (Rawlinson and Fishwick, 2012). To overcome this issue with the WOMBAT dataset, the AuSREM P-wave mantle velocity model (Kennett and Salmon, 2012; Kennett et al., 2013) is used in the starting model. This model is defined on a $0.5^{\circ}$ grid in latitude and longitude and $25 \mathrm{~km}$ in depth from the base of the crust to a depth of $350 \mathrm{~km}$. Much of the constraint on P-wave velocity in the AuSREM model comes from surface wave and body wave studies using continent-wide portable broadband arrays with station spacings upward of $250 \mathrm{~km}$ (Fishwick et al., 2005). This explains the relatively long wavelength structure that can be observed in the starting model (Figure DR2). Nonetheless, it is ideal for the purposes of this study in that it captures the broad velocity variations that the relative arrival time datasets are not sensitive to.

\section{DEPTH TO BASE OF LITHOSPHERE}

The depth to the base of the lithosphere is in general difficult to estimate as it is not usually marked by a significant discontinuity in velocity or other seismic property (Obrebski et al., 2011). The AuSREM reference model (Kennett and Salmon, 2012) includes an estimate of depth to the base of the lithosphere, made using multiple estimators including analysis of refracted waves in the mantle, and velocities and velocity gradients deduced from surface-wave tomography and body-wave tomography. In order to produce the estimate of depth to the base of the lithosphere for the study region shown in Figure 2, the average vertical velocity in the upper mantle is used as a proxy, with the upper and lower limits calibrated to the AuSREM reference model. Although this is an approximate approach which assumes that thicker lithosphere has higher wavespeeds, application to the starting model (Figure DR2) yields a pattern of depth variations very similar to the AuSREM model. The result shown in Figure 2a is obtained by applying the same approach to the final model (Figure 1) and using a moving average filter to remove very short wavelength structure. For the purposes of geodynamic modelling, only the first-order features - which are the most robust - are used (Figure 2b).

\section{SYNTHETIC RESOLUTION TESTS}

Raypath coverage (Figure DR3) provides qualitative insight into the ability of the seismic dataset to constrain structure. However, in 3-D meaningful visualization is difficult, and a more robust approach is to perform a synthetic checkerboard resolution test. To do so, an alternating pattern of higher and lower wavespeeds is generated that spans the 3-D model region (Figure DR4). Solving the forward problem of traveltime prediction through this model, using exactly the same sources, receivers and phase types as the WOMBAT dataset, allows a synthetic dataset to be generated. To this dataset, random noise with a Gaussian distribution and standard deviation of $67 \mathrm{~ms}$ is added to simulate the effects of picking uncertainty. Following this step, the data are 
inverted using identical parameters (grid spacing, smoothing and damping, number of iterations) to those used for the WOMBAT dataset, which results in a reconstruction of the checkerboard model (Figure DR5), the fidelity of which depends on the resolving power of the dataset.

\section{2-D AND 3-D GEODYNAMIC MODELS}

In this study, incompressible, Boussinesq, instantaneous flow models (flow velocities and viscosities are determined in the presence of a prescribed temperature/density field) with a composite Newtonian and non-Newtonian rheology (depending on temperature, pressure and strain rate - see below) are used to investigate a casual mechanism for intraplate volcanism beneath the NVP. Calculations are undertaken using the recently developed Fluidity computational framework, which has been extensively validated for geodynamical simulations, against both analytical and benchmark solutions (Davies et al., 2011; Kramer et al., 2012; Le Voci et al., 2014; Garel et al., 2014). Our goal in this study is to ascertain whether or not upwelling flow can be localised to the vicinity of the NVP - it is not to understand the time-dependence or evolution of the NVP (or surrounding lithospheric structure), which motivates the use of instantaneous flow models.

Our numerical simulations are undertaken in a domain that extends to $700 \mathrm{~km}$ depth, although results are consistent with $2900 \mathrm{~km}$ deep models with a factor of 30 increase in viscosity at 660 $\mathrm{km}$ depth. For 2-D cases, domain width is set at $2100 \mathrm{~km}$ (resulting in an aspect ratio of 3:1): tests with larger aspect ratios yield almost identical results. In 3-D cases, the domain extends $4200 \mathrm{~km}$ in N-S and E-W directions. For the majority of cases, free slip boundary conditions are imposed on all model boundaries. However, where we examine the effect of shear between the mantle and lithosphere on EDC, Couette velocity boundary conditions are imposed on all vertical boundaries. Temperature boundary conditions are fixed to $300 \mathrm{~K}$ at the surface and 1573 $\mathrm{K}$ at the domain's base.

\section{RHEOLOGICAL MODEL}

Diffusion and dislocation creep viscosities, $\mu$, are calculated via:

$$
\mu_{\text {diff/disl }}=A^{-\frac{1}{n}} \exp \left(\frac{E+P V}{n R T_{m}}\right) \dot{\varepsilon}_{\text {II }}^{\frac{1-n}{n}},
$$

with $A$ a generic prefactor with no explicit dependency on water content and grain size, $n$ the stress exponent; $E, V$ the activation energy and volume, respectively; $P=\rho_{0} g z$ is the lithostatic pressure, $R$ is the gas constant, and $\dot{\varepsilon}_{\text {II }}$ the second invariant of the strain rate tensor. $T_{m}$ is mantle temperature, obtained by adding an adiabatic gradient of $0.5 \mathrm{~K} / \mathrm{km}$ to the Boussinesq temperature solution. These are subsequently combined via a harmonic mean. The activation parameters and stress-dependent exponent used are consistent with those derived from experimental data on olivine (e.g. Karato and $\mathrm{Wu}, 1993)$. Prefactors for diffusion creep are tailored to yield a minimum asthenosphere diffusion creep viscosity of $\sim 5 \times 10^{19} \mathrm{~Pa}$.s, which is consistent with joint estimates from glacial rebound and inferences from plate dynamics (Iaffaldano and Lambeck, 2014), in addition to observations of seismic anisotropy beneath the Pacific basin (Gaboret et al., 2003). Prefactors for dislocation creep are set such that dislocation creep dominates in the vicinity of the edge driven convection cell and in the asthenosphere beneath fast 
moving plates (Debayle and Ricard, 2013). Figure DR6 illustrates the spatial distribution of viscosity and the dominant deformation mechanism for an example 2-D numerical experiment. Minimum dislocation creep viscosities vary between cases, but are generally $\sim 3 \times 10^{19} \mathrm{~Pa}$.s.

\section{2-D GEODYNAMIC EXPERIMENTS: RESULTS}

We run a series of 2D simulations to examine the relationship between the morphology and strength of EDC and two key geometrical parameters: (i) step-height; and (ii) transition distance. We also examine the sensitivity of results to surface plate motions, thus accounting for potential contributions from SDU. In the first test (Figure DR7, left) we vary the height of the lithospheric step by altering the thermal age of cratonic lithosphere $\left(\mathrm{Age}_{\mathrm{C}}=30-200 \mathrm{Myr}\right)$, while maintaining a constant horizontal transition length $(200 \mathrm{~km})$, in models where no plate motion is imposed. Results demonstrate that upwelling and downwelling velocities increase with step-height and the horizontal extent of the upwelling region increases (i.e. positive flow extends further along the $x$-axis). Furthermore, upwellings and downwellings are asymmetric, with downwellings stronger and more focussed. As illustrated by Figure DR7 (middle), when the transition length is increased (for models where $\mathrm{Age}_{\mathrm{C}}$ and $\mathrm{Age}_{\mathrm{P}}$ are set to 100 and $20 \mathrm{Myr}$, respectively), the cell moves further away from the step base and the asymmetry between upwelling and downwelling flow, observed in Figure DR7 (left), decreases. The effect of incorporating and varying plate velocity can be observed in Figure DR7 (right): as plate velocity increases, so does the distance of the convecting cell from the step, while upwelling velocities also increase (with corresponding downwelling velocities decreasing), highlighting the important role for SDU in controlling the location and magnitude of edge-driven cells. For all cases examined, peak velocities are significantly higher when the effects of dislocation creep are accounted for. These tests provide valuable insight into how the location, geometry and dynamics of EDC cells vary as a function of the three most important controlling parameters. 


\section{TABLES}

Table DR1

Key model parameters.

\begin{tabular}{|c|c|c|c|}
\hline \multicolumn{4}{|c|}{ Physical parameters } \\
\hline Quantity & Symbol & Units & Value \\
\hline Gravity & $g$ & $\mathrm{~m} \mathrm{~s}^{-2}$ & 9.8 \\
\hline Thermal expansivity coefficient & $\alpha$ & $\mathrm{K}^{-1}$ & $3 \times 10^{-5}$ \\
\hline Thermal diffusivity & $\kappa$ & $\mathrm{m}^{2} \mathrm{~s}^{-1}$ & $1 \times 10^{-6}$ \\
\hline Reference density & $\rho_{0}$ & $\mathrm{~kg} \mathrm{~m}^{-3}$ & 3300 \\
\hline Surface temperature & $T_{0}$ & K & 300 \\
\hline Mantle temperature & $T_{m}$ & $\mathrm{~K}$ & 1573 \\
\hline Gas constant & $R$ & $\mathrm{~J} \mathrm{~K}^{-1} \mathrm{~mol}^{-1}$ & 8.3145 \\
\hline \multicolumn{4}{|c|}{ Diffusion creep } \\
\hline Activation energy & $E$ & $\mathrm{~kJ} \mathrm{~mol}^{-1}$ & 300 \\
\hline Activation volume & $V$ & $\mathrm{~cm}^{3} \mathrm{~mol}^{-1}$ & 4.5 \\
\hline \multirow[t]{2}{*}{ Prefactor } & $A$ & $\mathrm{~Pa}^{-1} \mathrm{~s}^{-1}$ & $4.0 \times 10^{-10}$ \\
\hline & $n$ & - & 1 \\
\hline \multicolumn{4}{|c|}{ Dislocation creep } \\
\hline Activation energy & E & $\mathrm{kJ} \mathrm{mol}^{-1}$ & 540 \\
\hline Activation volume & $V$ & $\mathrm{~cm}^{3} \mathrm{~mol}^{-1}$ & 10 \\
\hline \multirow[t]{2}{*}{ Prefactor } & $A$ & $\mathrm{~Pa}^{-1} \mathrm{~s}^{-1}$ & $1.0 \times 10^{-15}$ \\
\hline & $n$ & - & 3.5 \\
\hline \multicolumn{4}{|c|}{ Limiters } \\
\hline Max. viscosity & $\mu_{\max }$ & $\mathrm{Pa} \mathrm{s}$ & $10^{24}$ \\
\hline Min. viscosity & $\mu_{\min }$ & $\mathrm{Pa} \mathrm{s}$ & $10^{19}$ \\
\hline
\end{tabular}




\section{FIGURES}

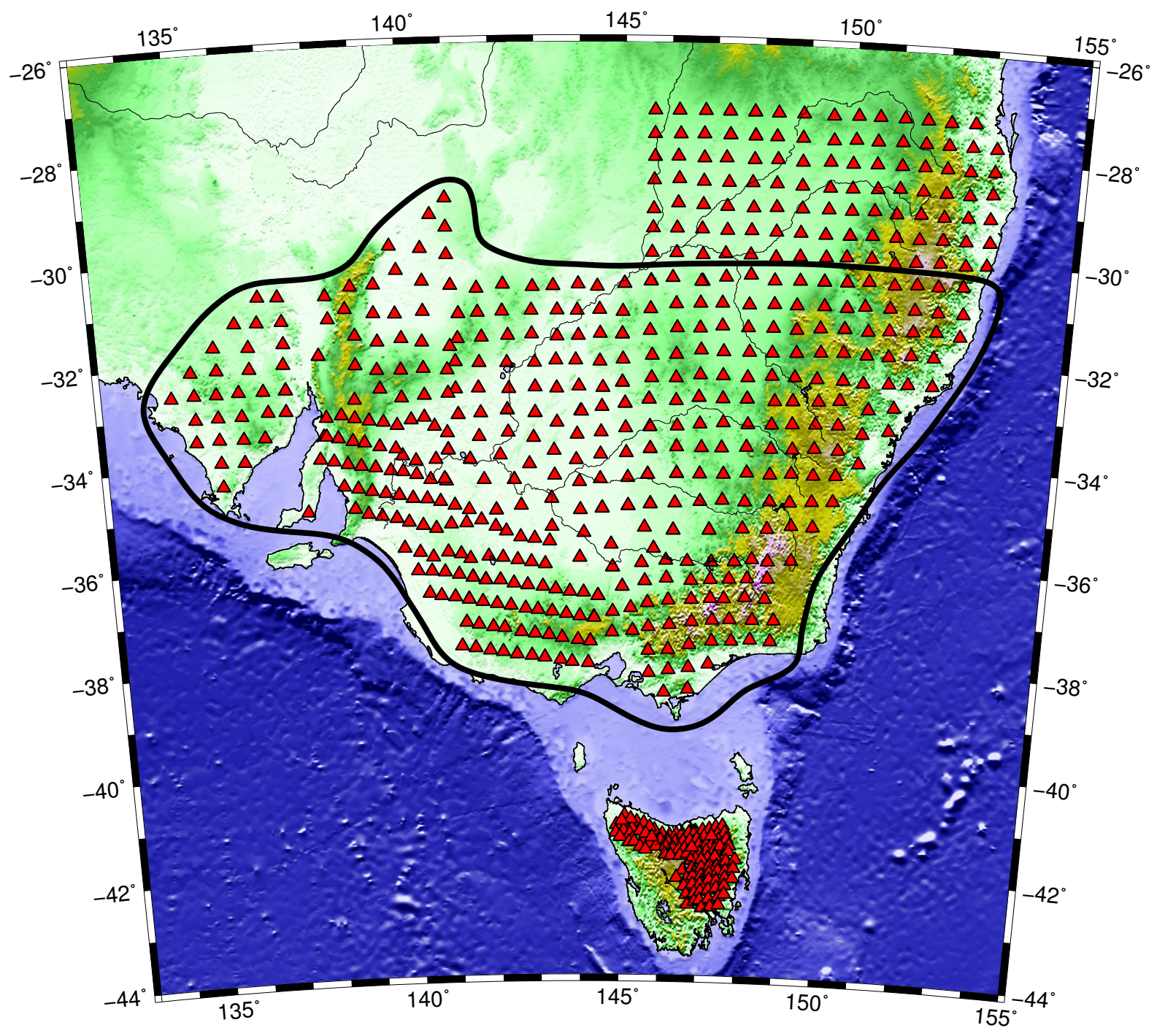

Figure DR1. Cumulative coverage of the WOMBAT transportable seismic array in southeast Australia, which has operated from 1998 to 2014. The thick black line encompasses the stations (red triangles) which provided data for the current study. This corresponds to a total of 12 sub-arrays, which together span all of Victoria, southeast South Australia and southern New South Wales. 

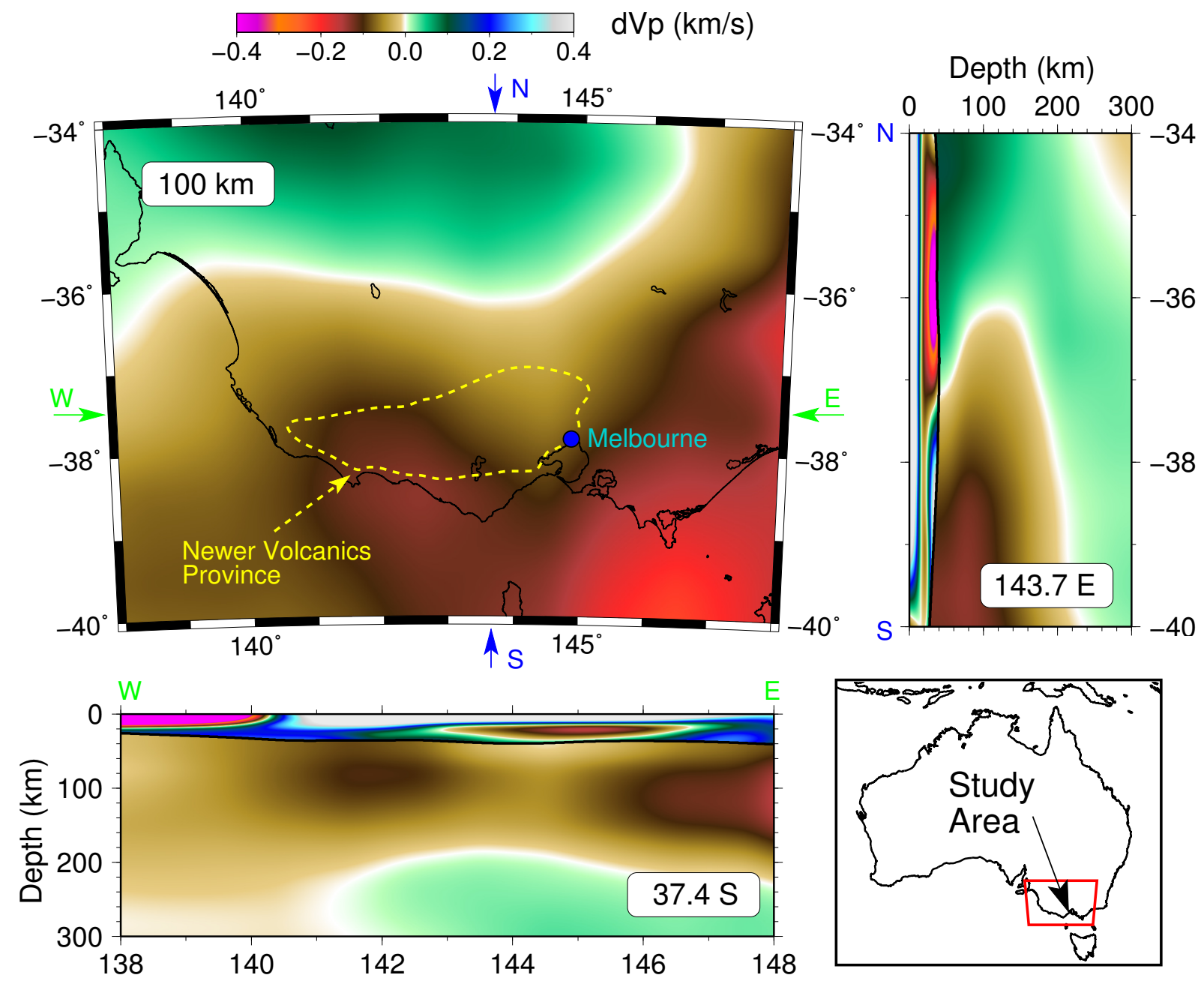

Figure DR2. Background reference model used to account for the presence of long wavelength structure that the teleseismic arrival time residuals poorly constrain due to the use of a transportable array of recorders. Note that there is no evidence of the NVP since it is a small scale feature and AuSREM, the reference model we use, is based on seismic structure derived from broadband station data which have an average spacing in excess of $250 \mathrm{~km}$. The basic trend from higher velocities in the NW to lower velocities in the SE can be attributed to gradual thinning of the lithosphere towards the passive margin of the Australian continent. 


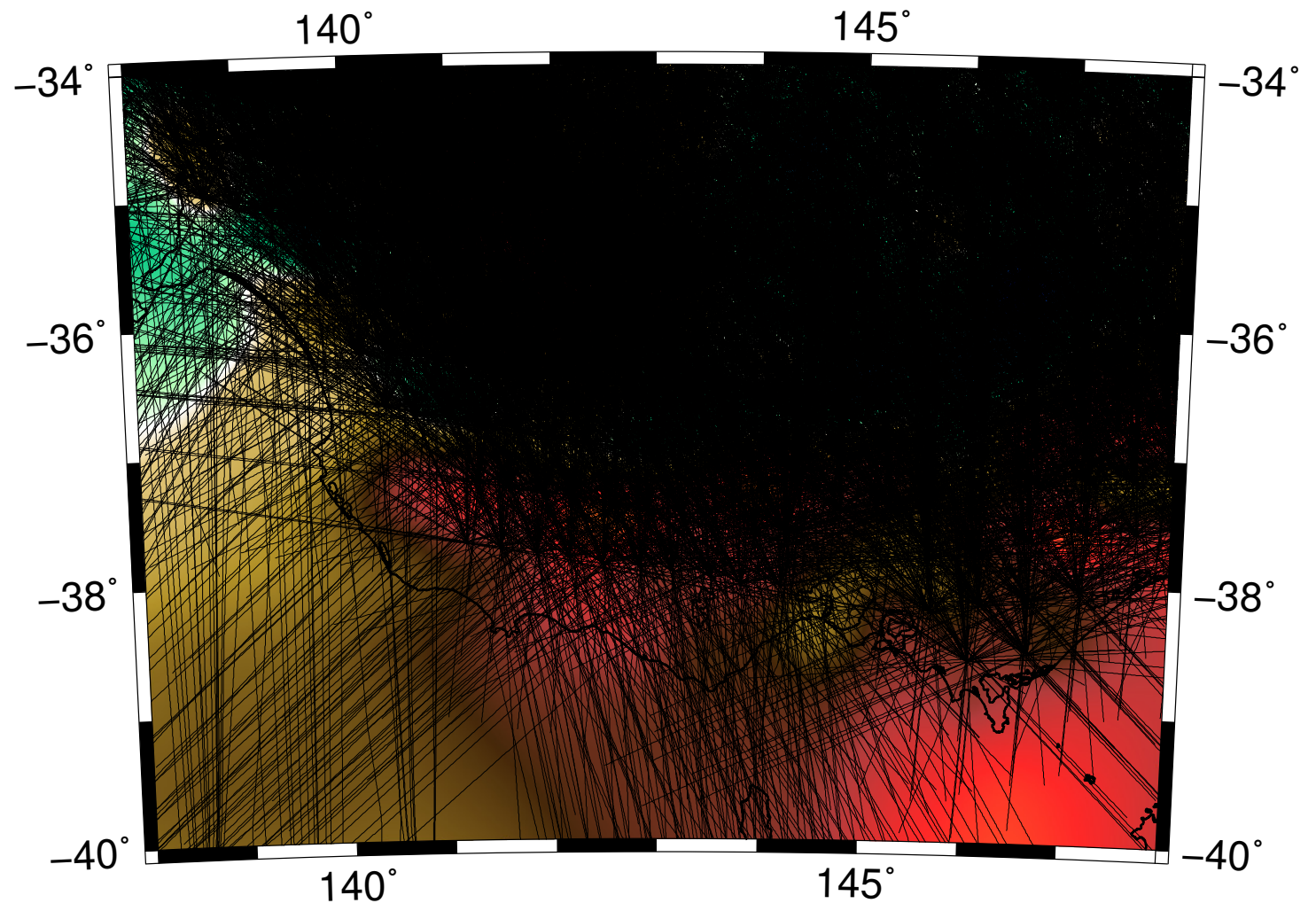

Figure DR3. Raypaths through the 3-D tomographic model shown in Figure 1, projected onto a $100 \mathrm{~km}$ depth slice. Path coverage is dense, but does gradually decrease towards the coast, particularly in the south and south-west. This is due to both the array coverage and the limited number of teleseismic earthquakes to the south and southwest. 


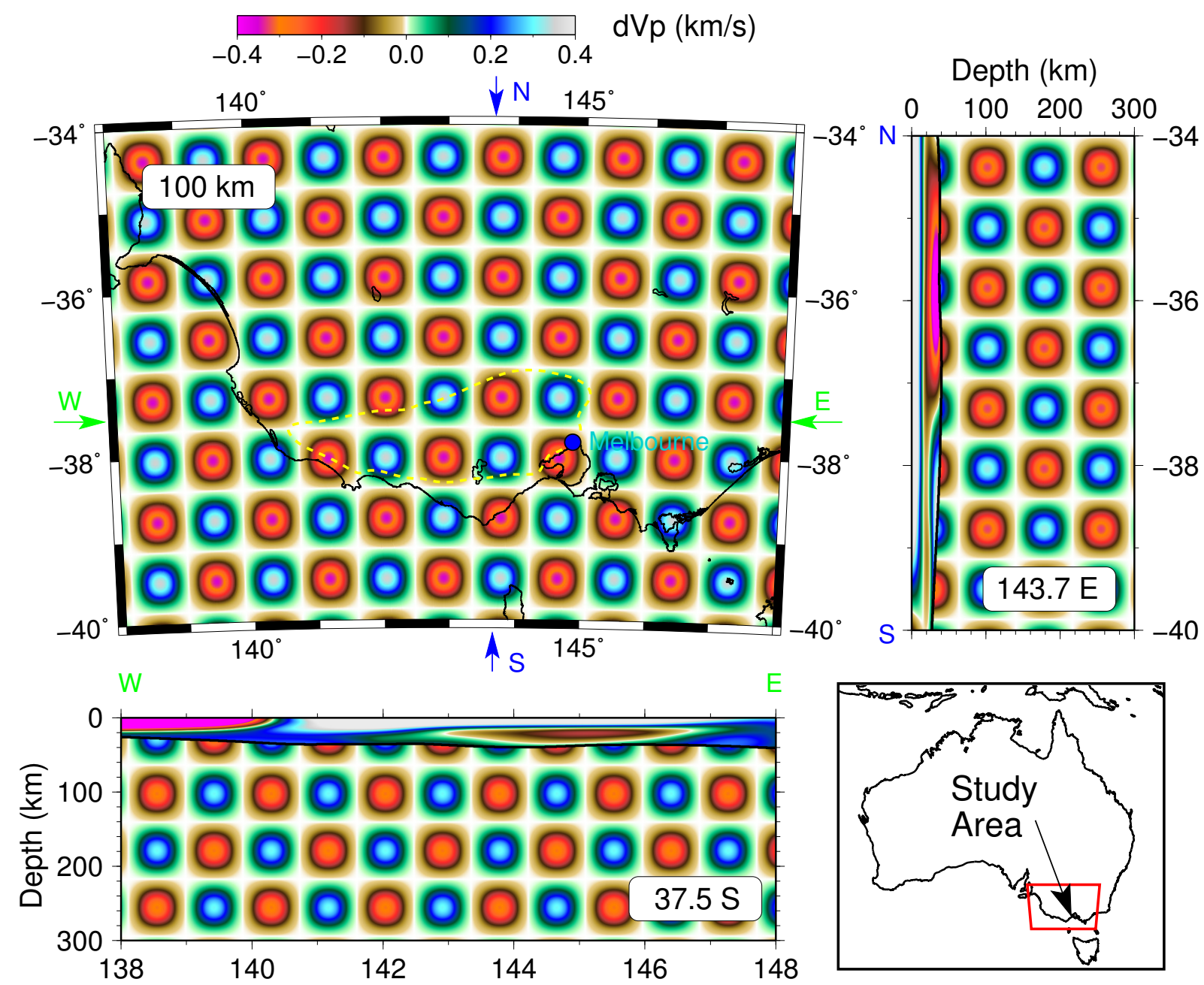

Figure DR4. Synthetic checkerboard model used to assess the robustness of the solution model. A synthetic dataset is generated by solving the forward problem in the presence of this model using the identical source-receiver configuration and phases that comprise the WOMBAT dataset. Random noise with a Gaussian distribution (standard deviation set to $67 \mathrm{~ms}$, equal to the noise estimate of the WOMBAT dataset) is added to the residual dataset to simulate the effect of picking uncertainty. 


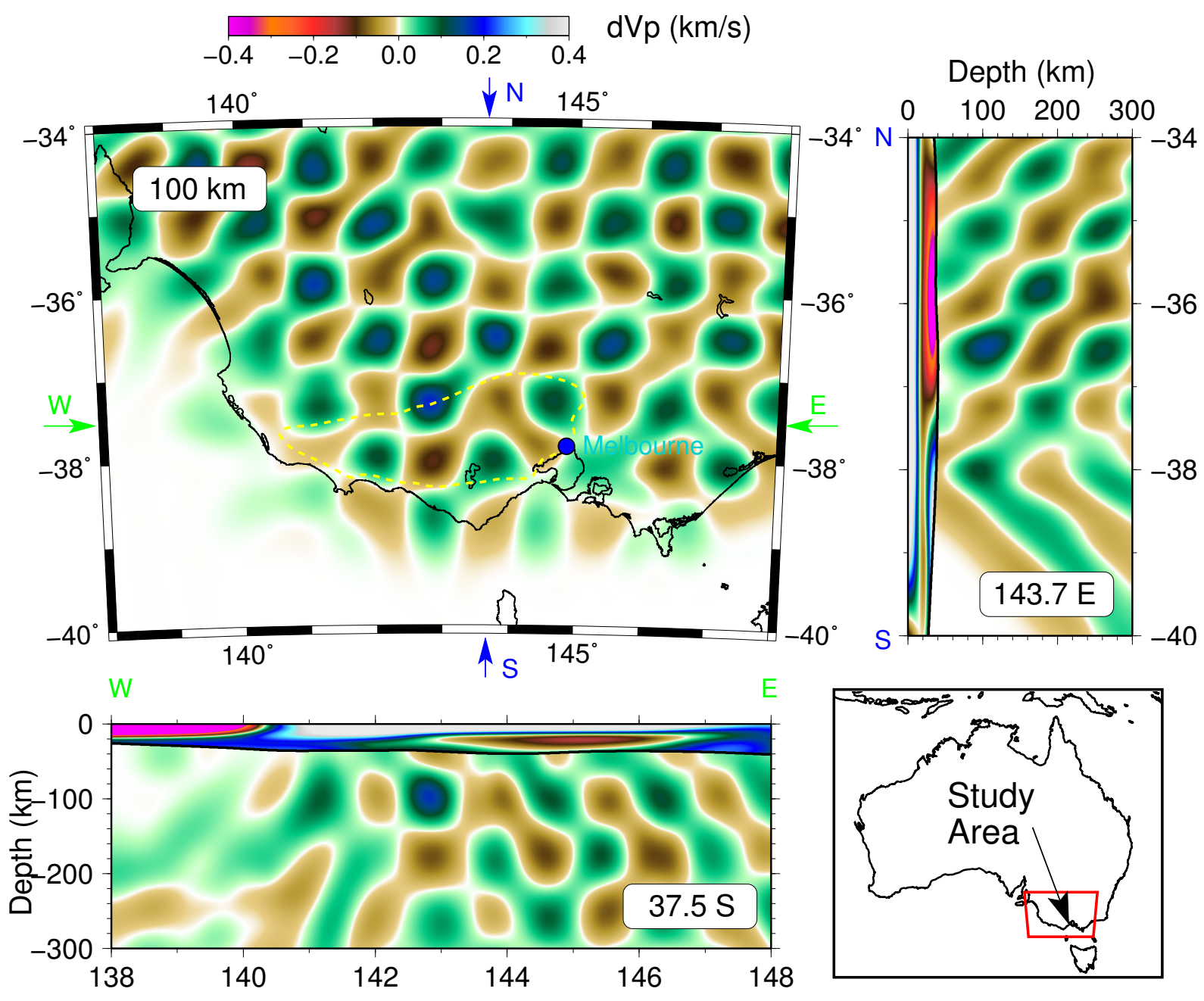

Figure DR5. Reconstruction result of the synthetic test (compare with previous figure). In general, the pattern of residuals is well recovered, although - as is typical with iterative non-linear schemes which rely on damping and smoothing regularisation - the amplitude of anomalies tends to be underestimated. The region below the NVP is well resolved, although to the south and west, the accuracy of the recovery tends to decrease. 
(a) 2-D Model Setup

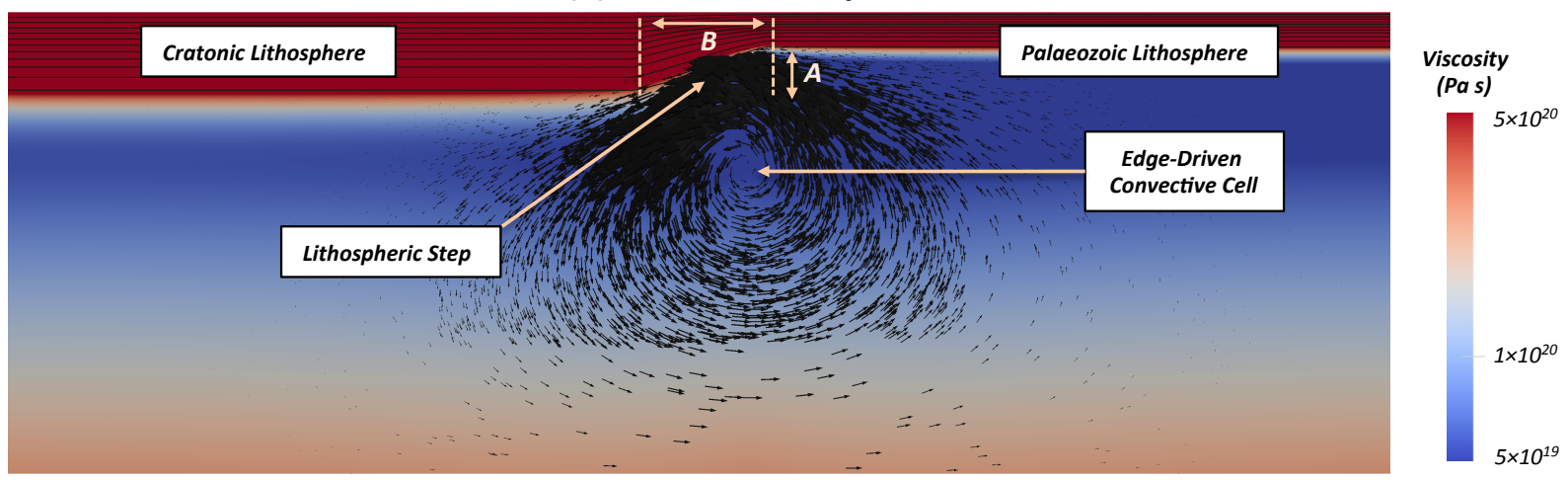

(b) Dominant Deformation Mechanism

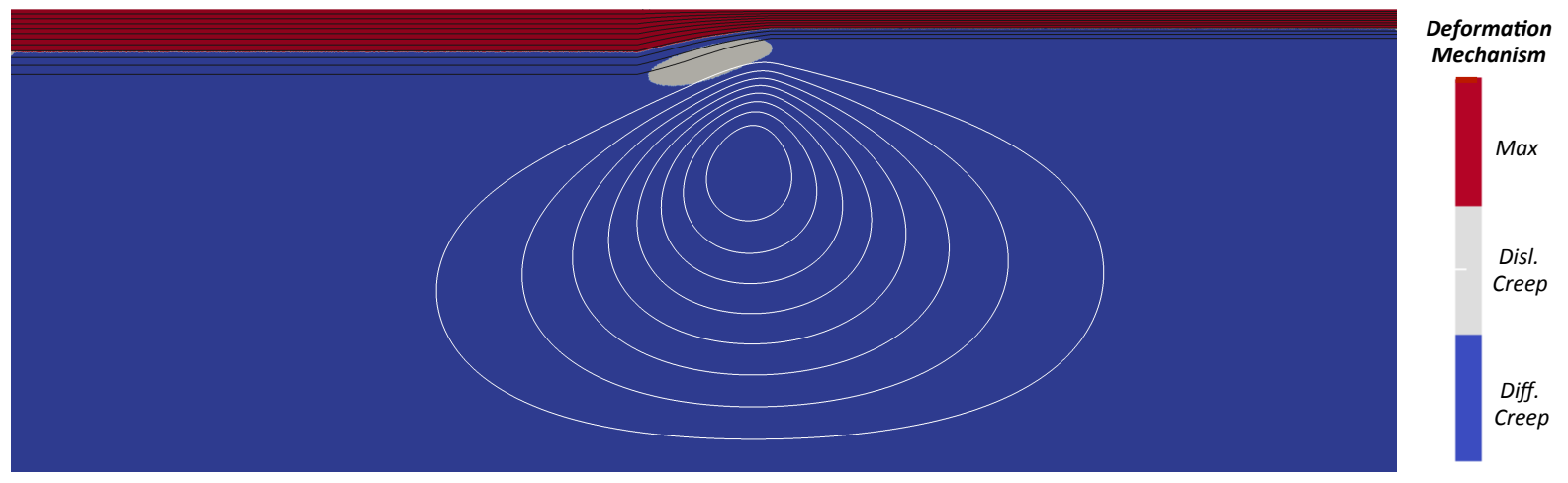

Figure DR6. (a) Viscosity field (on a logarithmic scale) from an example 2-D case, alongside temperature contours (black, ranging between $300 \mathrm{~K}$ and $1400 \mathrm{~K}$, in $100 \mathrm{~K}$ intervals), and glyphs of the velocity field (the largest glyph denotes a velocity of $1.0 \mathrm{~cm} / \mathrm{yr}$ ), illustrating the convective cell that is induced adjacent to a lithospheric step. In the example shown, cratonic lithosphere, with a thermal age of $100 \mathrm{Myr}\left(\mathrm{Age}_{\mathrm{C}}\right.$, defined via a half-space cooling model), is located on the left hand side of the domain, with $20 \mathrm{Myr}$ old Palaeozoic lithosphere (Agep) on the domain's right hand side; (b) A map of the dominant deformation mechanism, alongside contours of temperature and the stream-function, for the case illustrated in panel a, where viscosity is governed by both diffusion and dislocation creep. Upper mantle deformation is typically accommodated via diffusion creep, although due to locally higher strain-rates, dislocation creep is dominant in the vicinity of the convective cell (and at the base of the lithosphere in cases where surface plate motion is considered), leading to a local decrease in viscosity and a corresponding increase in velocity. 

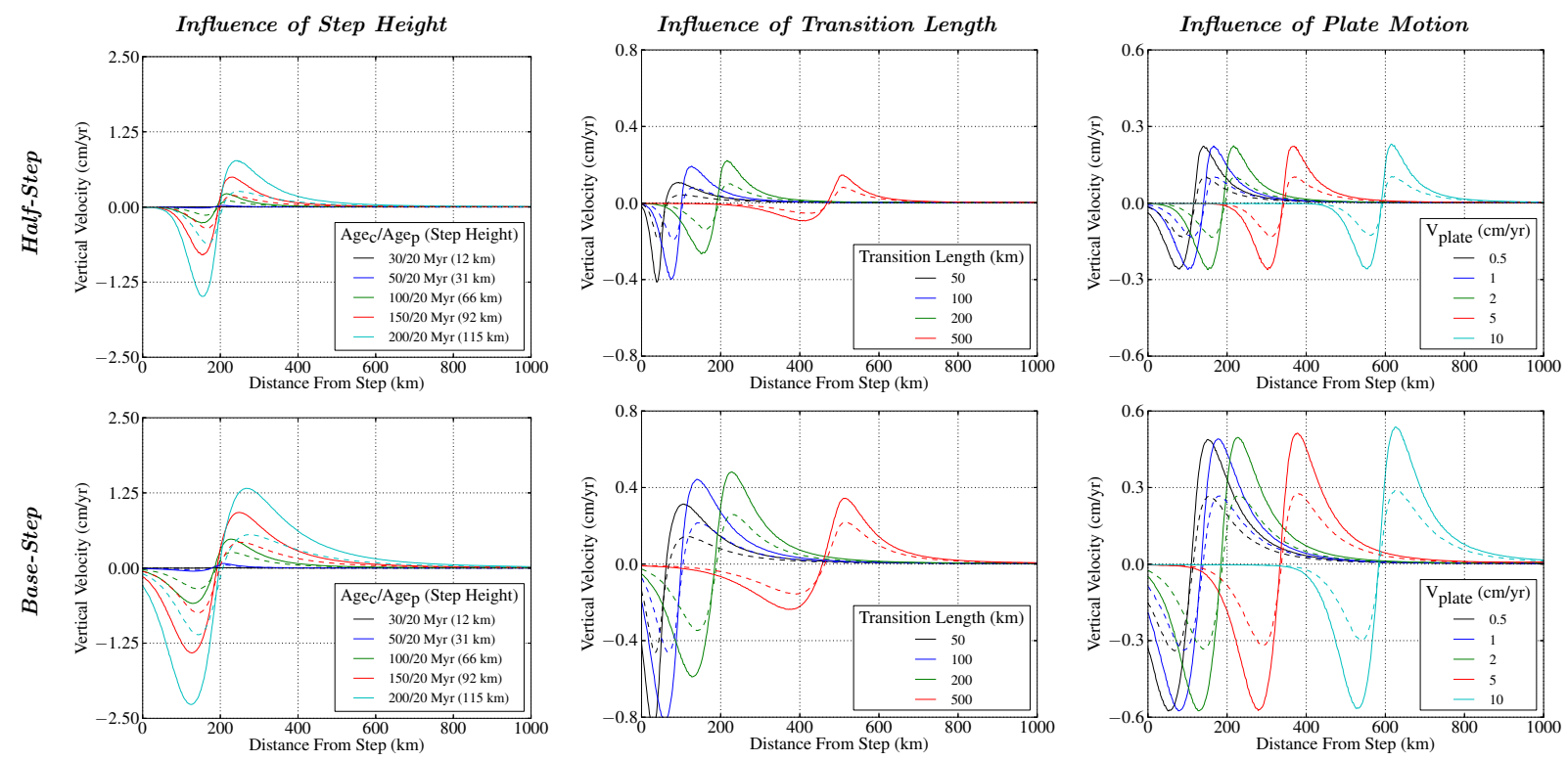

Figure DR7. Influence of step height, transition length and plate motion on upwelling velocities adjacent to a lithospheric step, with velocities measured (top) at the half-way point between Palaeozoic and cratonic lithosphere, and (bottom) at the base of the step (i.e. the depth where cratonic lithosphere starts to transition towards Palaeozoic lithosphere). For cases with 30, 50, 100, 150 and $200 \mathrm{Myr}$ old cratonic lithosphere, the half-step depths are 59, 68.5, 86, 99 and $110.5 \mathrm{~km}$, respectively. For these cases, the base of the step (the depth of the $1400 \mathrm{~K}$ isotherm) is at a depth of $65,84,119,145$ and $168 \mathrm{~km}$. Results are presented for cases with diffusion creep only (dashed lines) and a composite diffusion/dislocation creep (continuous lines). Note that for the cases shown, mean asthenospheric viscosities are $\sim 5.0 \times 10^{19} \mathrm{~Pa}$ s. 
(a) NVP cell: No Plate Motion

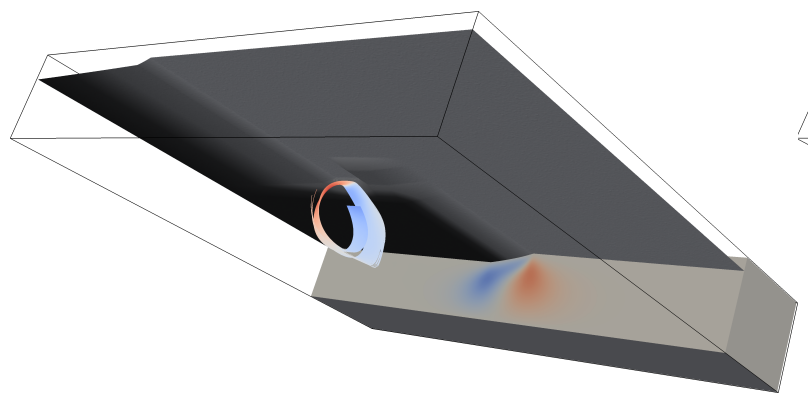

(c) Eastern cell: No Plate Motion
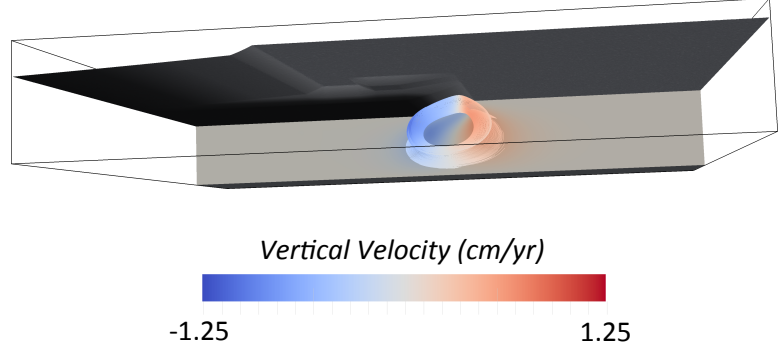

(b) NVP cell: Plate Motion

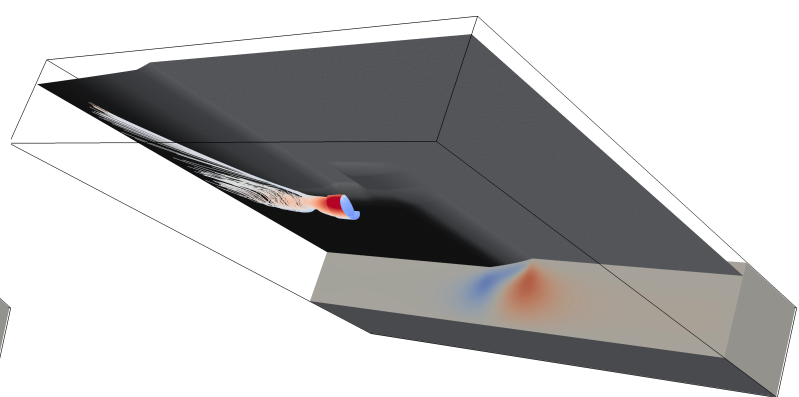

(d) Eastern cell: Plate Motion

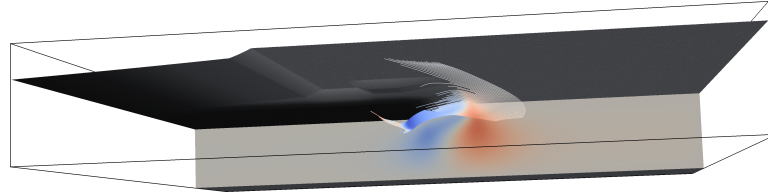

Depth (km)

100

250

Figure DR8. An alternative illustration of the 3-D geodynamic experiments presented in Figure 3, in addition to an identical case without plate motion. Images include: (i) a temperature isosurface at $1400 \mathrm{~K}$, coloured by depth, which approximates the base of the lithosphere; (ii) a clipped surface, coloured by vertical velocity; and (iii) stream-tracers, coloured by vertical velocity, to highlight the flow field. These figures demonstrate that in the absence of plate motion, a strong edge-driven convective 'cell' is generated at the N-S oriented lithospheric step to the east of the NVP. Furthermore, the radius of the convective cell beneath the NVP is greatly increased (cell penetrates much deeper), when compared to the case with plate motion. The 'eastern' cell, however, is distorted by motion of the Australian plate, as its axis lies parallel to the direction of plate motion. The axis of the NVP cell, on the other hand, lies perpendicular to the direction of plate motion and, accordingly, the upwelling is enhanced, reflecting the important contribution of SDU to mantle flow. 


\section{REFERENCES CITED}

Davies, D.R., Wilson, C.R., and Kramer, S.C., 2011, Fluidity: A fully unstructured anisotropic adaptive mesh computational modeling framework for geodynamics: Geochem. Geophys. Geosyst., v. 12, p. Q06,001.

Debayle, E., and Ricard, Y., 2013, Seismic observations of large-scale deformation at the bottom of fast-moving plates: Earth Planet. Sci. Lett., v. 376, p. 165-177.

Fishwick, S., Kennett, B.L.N., and Reading, A.M., 2005, Contrasts in lithospheric structure within the Australian craton - insights from surface wave tomography: Earth Planet. Sci. Lett., v. 231, p. 163-176.

Gaboret, C., Forte, A.M., and Montagner, J.P., 2003, The unique dynamics of the Pacific Hemisphere mantle and its signature on seismic anisotropy: Earth Planet. Sci. Lett., v. 208, p. 219233.

Garel, F., Goes, S., Davies, D.R., Davies, J.H., Kramer, S.C., and Wilson, C.R., 2014, Interaction of subducted slabs with the mantle transition-zone: A regime diagram from 2-D ther mo-mechanical models with a mobile trench and an overriding plate: Geochem. Geophys. Geosys., v. 15, p. 1739-1765, doi:10.1002/2014GC005257.

Iaffaldano, G., and Lambeck, K., 2014, Pacific plate-motion change at the time of the HawaiianEmperor bend constrains the viscosity of Earth's asthenosphere: Geophys. Res. Lett., v. 15, p. 3398-3406, doi:10.1002/2014GL059763.

Karato, S.I., and Wu, P., 1993, Rheology of the upper mantle: A synthesis: Science, v. 260, p. 771-778.

Kennett, B.L.N., Fichtner, A., Fishwick, S., and Yoshizawa, K., 2013, Australian Seismological Reference Model (AuSREM): mantle component: Geophys. J. Int., v. 192, p. 871-887.

Kennett, B.L.N., and Salmon, M., 2012, AuSREM: Australian seismological reference model: Australian Journal of Earth Sciences, v. 59, p. 1091-1103.

Kennett, B.L.N., Sambridge, M.S., and Williamson, P.R., 1988, Subspace methods for large scale inverse problems involving multiple parameter classes: Geophys. J., v. 94, p. 237-247.

Kramer, S.C., Wilson, C.R., and Davies, D.R., 2012, An implicit free-surface algorithm for geodynamical simulations: Phys. Earth Planet. Int., v. 194, p. 25-37, doi: 10.1016/j.pepi.2012.01.001.

Le Voci, G., Davies, D.R., Goes, S., Kramer, S.C., and Wilson, C.R., 2014, A systematic 2-d investigation into the mantle wedge's transient flow regime and thermal structure: Complexities arising from a hydrated rheology and thermal buoyancy: Geochemistry, Geophysics, Geosystems, v. 15, p. 28-51.

Obrebski, M., Allen, R.M., Pollitz, F., and Hung, S.H., 2011, Lithosphere-asthenosphere interaction beneath the western United States from the joint inversion of body-wave traveltimes and surface-wave phase velocities: Geophys. J. Int., v. 185, p. 1003-1021.

Rawlinson, N., and Fishwick, S., 2012, Seismic structure of the southeast Australian lithosphere from surface and body wave tomography: Tectonophysics, v. 572, p. 111-122.

Rawlinson, N., and Kennett, B.L.N., 2008, Teleseismic tomography of the upper mantle beneath the southern Lachan Orogen, Australia: Phys. Earth Planet. Inter., v. 167, p. 84-97.

Rawlinson, N., Pozgay, S., and Fishwick, S., 2010, Seismic tomography: A window into deep Earth: Phys. Earth Planet. Inter., v. 178, p. 101-135.

Rawlinson, N., and Sambridge, M., 2003, Seismic traveltime tomography of the crust and lithosphere: Advances in Geophysics, v. 46, p. 81-198.

Rawlinson, N., and Sambridge, M., 2004a, Multiple reflection and transmission phases in com- 
plex layered media using a multistage fast marching method: Geophysics, v. 69, p. 13381350.

Rawlinson, N., and Sambridge, M., 2004b, Wavefront evolution in strongly heterogeneous layered media using the fast marching method: Geophys. J. Int., v. 156, p. 631-647.

Rawlinson, N., and Urvoy, M., 2006, Simultaneous inversion of active and passive source datasets for 3-D seismic structure with application to Tasmania: Geophys. Res. Lett., v. 33, p. L24,313. 